Dr RATOMIR MILIKIĆ, viši naučni saradnik

Institut za savremenu istoriju

Beograd, Republika Srbija

UDK 327(497.1:498)"1941"

rasamilikic@gmail.com

94:341.7(497.1:498)"1941"

originalan naučni rad / original scientific paper

primljeno / received: 30. 11. 2020.

prihvaćeno / accepted: 24. 11. 2021.

https://doi.org/10.29362/ist20veka.2022.1.mil.73-88

\title{
POVLAČENJE JUGOSLOVENSKOG DIPLOMATSKOG OSOBLJA IZ KRALJEVINE RUMUNIJE 1941. GODINE
}

APSTRAKT: $U$ članku se rekonstruiše povlačenje jugoslovenskog osoblja iz diplomatskog predstavništva u Kraljevini Rumuniji 1941, posle aprilskog napada Nemačke na Kraljevinu Jugoslaviju. To povlačenje se umnogome razlikovalo od povlačenja jugoslovenskog osoblja iz drugih država koje su preko noći postale neprijateljske. Kraljevina Rumunija je jugoslovenskom diplomatsko/konzularnom osoblju uskratila gostoprimstvo tek 14. maja 1941, ali te ljude nije poslala u Nemačku, gde se prisilno okupio veliki broj diplomata od kojih su mnogi potom odvedeni u koncentracione logore, nego ih je poslala na teritoriju neutralnih zemalja. Većina diplomatsko-konzularnog osoblja i drugih građana koji su se zatekli u Rumuniji povukla se ili u pravcu Turske ili u pravcu Odese. Oni koji su prispeli u Carigrad stavili su se posle u službu Vlade Kraljevine Jugoslavije u emigraciji. Rad je zasnovan na arhivskoj građi Vlade Kraljevine Jugoslavije u emigraciji i na dnevnicima Koste St. Pavlovića, tada na diplomatskoj službi u Bukureštu.

KLJUČNE REČI: Kraljevina Jugoslavija, Kraljevina Rumunija, diplomatija, Drugi svetski rat, povlačenje diplomatskog osoblja, prekid bilateralnih odnosa

Kraljevina Rumunija i Kraljevina Srbija, a potom i SHS/ Jugoslavija, još od nastanka modernih država u 19 . veku razvijale su dobrosusedske odnose. ${ }^{1}$ Dunav koji ih je spajao, ali istovremeno i razdvajao, obuzdan je tek krajem 19. veka (prokopavanje kanala u Sipu i regulisanje plovidbe u rejonu Gvozdenih vrata). ${ }^{2}$ Obe zemlje su polagale nadu da će se njihovi sunarodnici koji su živeli u

\footnotetext{
${ }^{1}$ Prvi diplomatski odnosi ustanovljeni su aprila 1841, kada je agent kneza Miloša George Germani stigao u prestonicu Vlaške.

${ }^{2}$ Sipski kanal, kao posebno komplikovan građevinski poduhvat, omogućio je da se konačno reši do tada izuzetno težak plovni put kroz Đerdapsku klisuru. Svečano su ga otvorila tri monarha, car Franja Josif, kraljevi Aleksandar Obrenović i Karol I Rumunski 17. septembra 1896. O razvoju plovidbe na Dunavu videti u: Milan Gulić, Kraljevina Jugoslavija i Dunav (Beograd: Institut za savremenu istoriju, 2014); Mladen St. Đuričić, Istorija jugoslovenskog rečnog parobrodarstva do 1926. godine (Beograd: Zavod za izdavanje udžbenika, 1965).
} 
okvirima Austro-Ugarske, posebno na području potonje Vojvodine i Transilvanije, ipak naći u granicama svojih matičnih država. To se obistinilo nakon 1918. godine i kraja Velikog rata u kome su obe zemlje položile velike žrtve. Dve zemlje povezuje i to što su tokom rata ${ }^{3}$ njihove vlade morale u celosti ili većim de$\mathrm{lom}^{4}$ da napuste prostor svojih država. Isto tako, hiljade srpskih vojnika su poginule za savezničku pobedu u Dobrudži, delu neokupirane rumunske teritorije.

Potpisivanje mirovnih ugovora i razgraničenje nakon propasti Centralnih sila donelo je izvesnu surevnjivost kod novonastalih ili proširenih država. ${ }^{5}$ Jedan od retkih primera potpuno mirnog razgraničenja, izvedenog uz sasvim ograničenu diplomatsku akciju, bilo je ustanovljenje granice između Kraljevine SHS i Kraljevine Rumunije u Banatu, gde je najveći deo teritorije koja je bila predmet razmatranja ostao u SHS (uz svesrdno zalaganje Mihajla Pupina), ali je zato najveći grad - Temišvar pripao Rumuniji. ${ }^{6}$

Dobrosusedski odnosi su se iz godine u godinu produbljivali. Prvo su uspostavljene posebne veze između kraljevskih dinastija dve zemlje, koje su krunisane venčanjem kralja Aleksandra I Karađorđevića i princeze Marije Minjon. Taj brak je dodatno osnažio veze dve dunavske kraljevine. ${ }^{7}$

Odnosi dve kraljevine su išli uzlaznom putanjom od perioda pre Balkanskih ratova. Temelje te saradnje u modernom dobu postavili su predsednici vlada Nikola Pašić i Tito Majoresku. Saradnja je uzdignuta na viši nivo stvaranjem Male Antante (prestala da postoji marta 1939. nestankom Čehoslovačke) koju su formirali ministri inostranih poslova Momčilo Ninčić i Take Jonesku, uz svesrdno zalaganje tadašnjeg šefa čehoslovačke diplomatije i potonjeg predsednika Edvarda Beneša. Ta saradnja je dodatno osnažena Balkanskim sporazumom koji su 9. februara 1934. potpisali ministri inostranih poslova Bogoljub Jeftić i Nikolae Titulesku, odnosno George Tataresku, zajedno s kolegama iz Grčke i Turske,

\footnotetext{
${ }^{3}$ Rumunija je u rat ušla 27. avgusta 1916. u nadi da će povratiti oblast Transilvanije i nakon protivofanzive Centralnih sila bila je primorana da napusti Bukurešt, a kralj, Vlada i državne institucije s vojskom povukli su se u Besarabiju. Tu su uspešno odolevali uz rusku pomoć i učešće saveznika, među kojima su bile i srpske trupe do novembra 1917. i Oktobarske revolucije u Rusiji.

${ }^{4}$ Vlada i vojska Rumunije su morale da se pod pritiskom Austro-Ugarske i Bugarske povuku u najudaljenije delove svoje teritorije iza Karpata.

${ }^{5}$ Ujedinjenje Rumunije sa Transilvanijom, proklamovano u Alba Longi 1. decembra 1918, potvrđeno je i Versajskim mirovnim ugovorom.

${ }^{6}$ Više u: Andrej Mitrović, Razgraničenje Jugoslavije sa Mađarskom i Rumunijom (Novi Sad: Prometej, 2019); Đorđe Stanković, Nikola Pašić, saveznici i stvaranje Jugoslavije (Beograd: Nolit, 1984), 175-179.

${ }^{7}$ Venčanje je održano 8. juna 1922. godine. Tom prilikom rumunska kraljevska porodica je došla u Beograd. Više u: Danica-Kaća Čolović i Srđan Čolović, Marija Karađorđević Kraljica-Majka (Beograd: Arhiv Srbije, 2001). Detalje organizacije samog venčanja videti u: Aleksandar Marinković, Ženidba kralja Aleksandra (Beograd: Vajat, 2004). Interesantno je napomenuti da je uspostavljanjem bračnih veza dve dinastije znatno povećan broj rumunskih državljana koji su dobili odlikovanja Kraljevine SHS/Jugoslavije. Njihov broj nimalo ne zaostaje za brojem državljana najbližeg saveznika Kraljevine - Republike Francuske, a značajno nadmašuje podanike ostalih prijateljskih zemalja. Videti u: Arhiv Jugoslavije (AJ), fond 334, Ministarstvo inostranih dela Kraljevine Jugoslavije, fascikla 709, (Protokol) Spisak odlikovanih stranih državljana najvišim redovima odlikovanja 1919-1932, koji je sačinila Kraljevska kancelarija ordena.
} 
Dimitrijem Maksimosom i Ruždijem Bejom (Balkanska antanta). Saradnja je počela da opada u doba Milana Stojadinovića i početka izbijanja političke krize u Rumuniji krajem tridesetih godina. ${ }^{8}$ Kraljevina Rumunija je tada bila rastrzana unutrašnjim političkim sukobima. Sukobi su posebno eskalirali kada je Gvozdena garda ubila predsednika vlade Armanda Kalineskua u septembru 1939. ${ }^{9}$

Zbog opšte situacije u Evropi, Rumunija se našla pod velikim pritiskom pojedinih zemalja sa kojima se graničila. Prvo je ustupila Besarabiju SSSR-u u julu 1940. Krajem avgusta iste godine bila je primorana da veliki deo Transilvanije ustupi Mađarskoj. U teškoj političkoj situaciji na vlast dolazi general Antonesku, a kralj Karol II je prinuđen da abdicira 6. septembra 1940. Pod vidom vojne pomoći odnosno obuke, tokom oktobra 1940. dolaze nemački „,instruktori“. Prvo je stiglo njih 12.000, da bi se u narednih osam meseci njihov broj povećao na gotovo pola miliona vojnika na rumunskoj teritoriji. Nastavljeno je komadanje rumunske teritorije, pa je Mirovnim ugovorom iz Krajove Južna Dobrudža predata Bugarskoj u septembru 1940. U januaru 1941. izbila je revolucija u Bukureštu kada je Gvozdena garda uz podršku pojedinih ministara u Vladi pokušala da preuzme vlast. General Antonesku se održao na vlasti, slomivši otpor revolucionara, a onda je preuzeo i funkciju ministra inostranih dela. Vladao je u skladu sa nemačkim željama i interesima. ${ }^{10}$

Odnosi sa Jugoslavijom ni u tim previranjima nisu bili narušeni, ali su donekle izgubili na intenzitetu. Prvi ambasador u istoriji jugoslovenske diplomatske službe bio je Jovan Dučić, koji je početkom 1939. godine proizveden u rang ambasadora a jugoslovensko predstavništvo u Bukureštu je uzdignuto u rang ambasade. ${ }^{11}$ Njegov naslednik od 1940. godine bio je Aleksandar Avakumović. ${ }^{12}$

Kada se sagleda sve izloženo, postavlja se opravdano pitanje kako je bilo moguće da se dve zemlje nađu na suprotnim stranama u Drugom svetskom ratu. Nakon puča 27. marta 1941, Ambasada Kraljevine Jugoslavije izveštava o veoma pozitivnom prijemu tog čina kod rumunskog naroda, ali ne i kod generala Antoneskua, niti kod rumunske Vlade. ${ }^{13}$ Ambasadora Avakumovića je vest o

\footnotetext{
${ }^{8}$ Više u: Milan Stojadinović, Ni rat ni pakt: Jugoslavija između dva rata (Rijeka: Otokar Keršovani, 1970).

${ }^{9} \mathrm{O}$ istoriji Rumunije i Rumuna više u: Ovidiju Pečikan, Istorija Rumuna (Beograd: Klio, 2015).

10 O. Pečikan, n. d.; Dennis Delent, Hitler's Forgotten Ally: Ion Antonescu and His Regime, Romania, 1940-1944 (London: Palgrave Macmillan, 2006). Više i u: Kosta St. Pavlović, Onakvi kakve sam ih znao (Beograd: Otkrovenje, 2004), 113-117.

${ }^{11}$ Detaljnije u: Srđan Mićić, Od birokratije do diplomatije - istorija jugoslovenske diplomatske službe 1918-1939 (Beograd: Institut za noviju istoriju Srbije, 2018), 231-236.

${ }^{12}$ Aleksandar Avakumović, iskusni karijerni diplomata, služio je i ranije u Rumuniji i važio za odličnog poznavaoca tamošnjih prilika. Posle evakuacije postavljen je za poslanika u Švedskoj, a nakon dolaska komunista na vlast u Jugoslaviji ostao je u emigraciji. AJ, 334-133, Personalni dosije A. Avakumovića.

${ }^{13}$ Više u: Radmila Radić, „Sećanje Koste St. Pavlovića“, Tokovi istorije, br. 1-2, (2009), 249304. U pitanju je spis koji je taj diplomata napisao u svojoj beležnici na brodu na putu ka Londonu u leto 1941. godine. Iako su pojedini segmenti tog teksta objavljeni u njegovom dnevniku i u drugim njegovim portretima pojedinih istorijskih ličnosti, ovaj Pavlovićev spis, koji je R. Radić priredila, posvećen je isključivo sagledavanju prilika u onovremenoj Rumuniji i stoga je nezaobilazan za proučavanje ove teme.
} 
puču zatekla u Beogradu. Odmah se vratio u Bukurešt i 28. marta preneo rumunskoj Vladi posebnu instrukciju Vlade generala Dušana Simovića da će Kraljevina Jugoslavija poštovati sve odredbe Pakta potpisanog sa Nemačkom 25. marta. Tom prilikom je iznet privatni stav jednog visokog zvaničnika rumunske Vlade da je rat sa Nemačkom neizbežan, o čemu je odmah izvešten Beograd. U razgovoru koji je Avakumović potom imao sa generalom Antoneskuom i o kome je takođe izvestio Beograd, izneta je bojazan da će Kraljevina Jugoslavija biti napadnuta uz konstataciju da će vojni položaj Jugoslavije u slučaju takvog napada biti izuzetno težak, ali su data i uveravanja da Rumunija neće samostalno napasti Jugoslaviju niti će učestvovati u operacijama protiv nje. ${ }^{14}$

Kosta St. Pavlović ${ }^{15}$ je iz posrednih izvora, kroz iskaz francuskih diplomata u Bukureštu, ostavio zapis o stavu rumunskog kralja i kraljice: kraljevski par je neskriveno podržao vojni puč od 27. marta u Beogradu. On navodi da je rumunska javnost podržala puč u Jugoslaviji 27. marta, da su studenti manifestovali, da je ambasada dobijala cveće i telefonske pozive podrške, a da su rumunski listovi pisali veoma pohvalno o mladom jugoslovenskom kralju Petru II (sinu rumunske princeze, jugoslovenske kraljice Marije Karađorđević). ${ }^{16}$

Ambasada je redovno izveštavala o brojnom stanju i položajima nemačkih trupa na teritoriji Rumunije, ali i o mogućnosti napada na Jugoslaviju. U noći između 5. i 6. aprila napad na Jugoslaviju otpočeo je upravo sa teritorije Rumunije, kada su nemačke specijalne jedinice zaposele Sipski kanal i Đerdap. Ujedno su tu pale prve srpske žrtve u kratkotrajnom, ali veoma krvavom Aprilskom ratu. ${ }^{17}$

Vredno je pomena svedočenje Koste St. Pavlovića zabeleženo nekoliko nedelja nakon povlačenja iz Rumunije o tome da je Ambasada 29. marta u tri navrata izvestila da će Nemci izvršiti vojni prepad na Sipski kanal, kao i da je još jedno upozorenje bilo otpravljeno neposredno po otpočinjanju Aprilskog rata, ali da se na ta obaveštenja Beograd oglušio. ${ }^{18}$

Kraljevina Jugoslavija je očekivala napad sa više strana, ali je jedino deo teritorije prema Rumuniji bio maltene samo simbolično branjen. Celu teritoriju Banata je branio Banatski odred, verovatno jedna od brojčano najslabijih vojnih

\footnotetext{
${ }^{14}$ Od svih suseda Kraljevine Jugoslavije koji su potpisali Trojni pakt jedino Kraljevina Rumunija nije aktivno učestvovala u napadu na Jugoslaviju, niti je posela deo jugoslovenske teritorije. Kako je poverljiva arhiva ambasade Kraljevine Jugoslavije u Rumuniji delimično uništena pre povlačenja, o sadržini ovog razgovora doznajemo iz detaljnog izveštaja ambasadora Avakumovića u Tel Avivu 29. maja 1941. AJ, fond 103, Emigrantska vlada Kraljevine Jugoslavije, fascikla 60, Izveštaj ambasadora Avakumovića od 29. maja 1941 (bez delovodnog broja).

${ }^{15}$ Kosta St. Pavlović, profesionalni diplomata poreklom iz diplomatske porodice, rođak i saradnik Slobodana Jovanovića. Tokom rata bio je šef kabineta predsednika u nekoliko vlada u emigraciji. Ostao je u Londonu nakon dolaska komunista na vlast 1945. Ostavio je izuzetno vredne dnevničke zapise, ali i nekoliko monografija i mnoštvo članaka o tom vremenu i njegovim savremenicima.

${ }^{16}$ Kosta St. Pavlović, Ratni dnevnik 1941-1945. (Beograd: Otkrovenje/Službeni glasnik, 2011), $540-541$.

17 Više o žrtvama u: Miloš Žikić, Na sporednom frontu - Aprilski rat i jugoslovensko-rumunski odnosi, zbornik radova sa bilateralnog skupa Instituta za savremenu istoriju i Univerziteta u Klužu (Kluž: Univerzitet u Klužu, 2019), u štampi.

${ }^{18}$ R. Radić, n. d., 262.
} 
jedinica. ${ }^{19}$ Nemačka vojska je odmah po otpočinjanju vojnih akcija počela da čisti teren. Tako su celokupno stanovništvo srpskog sela Sip, na desnoj strani Dunava, prisilno evakuisali na rumunsku stranu. U prolazne logore su smestili i zarobljene civilne brodare sa jugoslovenskih brodova, koji su odbili da se stave pod nemačku komandu. Najintenzivnije su korišćeni rumunski aerodromi sa kojih su nemački avioni izvršavali prva bombardovanja Beograda i severne teritorije Srbije. ${ }^{20}$

Sudeći po dopisima ambasade Kraljevine Jugoslavije u Bukureštu, Rumunija i general Antonesku su bili pod pritiskom Nemaca da rumunske trupe uđu u Banat i da nad delom te jugoslovenske teritorije uspostave civilnu kontrolu (pri tom se ne precizira na koji deo Banata se to odnosi). Takođe se ukazuje da je jugoslovenska vojska uzvratila i bombardovala rumunski pogranični grad Oršavu. ${ }^{21} \mathrm{Na}$ osnovu potonjeg sleda događaja, može se sa rezervom uzeti pomenuto pisanje jugoslovenskog diplomatskog predstavništva u Bukureštu. O bombardovanju Oršave nema podataka u srpskoj istoriografiji, pa je vrlo upitna verodostojnost te informacije. Svakako je pitanje posedanja jugoslovenske teritorije bilo postavljeno pred rumunske vlasti, ali za Treći rajh izgleda da to pitanje nije bilo od velikog značaja i ubrzo su odustali od njega. Rumunija im je poslužila kao izvesna „odskočna daska“ i kao platforma za napad na Jugoslaviju, a može se pretpostaviti da su se ideje o izvesnoj korekciji granica u Banatu mogle javiti u ranoj fazi planova za napad na Jugoslaviju kako bi podstakli rumunske vlasti da na to povoljnije gledaju. $\mathrm{Na}$ to su svakako uticale i značajne teritorijalne koncesije koje je Rumunija morala da istrpi u tom periodu, dajući velike teritorije svoje države Mađarskoj, Bugarskoj i SSSR-u. ${ }^{22}$ Takvo informisanje jugoslovenske ambasade bilo je u skladu sa onim što su im rumunski sagovornici iznosili, ali nije moglo da bude deo šire međunarodne slike, posebno imajući u vidu nedostatak dodatnih informacija. ${ }^{23}$

Ambasada Kraljevine Jugoslavije u Bukureštu otpočinjanjem ratnih dejstava ostaje faktički odsečena od matičnog Ministarstva inostranih poslova, kao i od Beograda. Prema rečima Koste St. Pavlovića, odmah su isečene telefonske veze jugoslovenske ambasade u Bukureštu. Nisu sačuvani direktni izveštaji kraljevske Ambasade o dešavanjima tokom Aprilskog rata, ali možemo na osnovu sećanja koja su ostavila dvojica diplomata da bar delimično rekonstruišemo njihov rad u tako teškim okolnostima. Među prvim potezima Ambasade bilo je da se i bez bližih instrukcija put

${ }^{19}$ Odred je u svom sastavu imao Gardijsku konjičku brigadu, jedan pešadijski i jedan konjički puk, jedan artiljerijski divizion i druge manje jedinice. Na graničnom frontu nalazile su se jedinice za zaštitu granice. Velimir Terzić, Slom Kraljevine Jugoslavije 1941. Uzroci i posledice poraza, knjiga 2 (Ljubljana-Beograd- Titograd: Narodna knjiga-Partizanska knjiga-Pobjeda, 1984), 258; M. Žikić, $n$. $d$.

${ }^{20}$ AJ, 103-60, Izjava Milana Đorđevića i Milutina Miloševića, činovnika Đerdapske administracije u prostorijama Ambasade Kraljevine Jugoslavije u Bukureštu od 9. aprila 1941. godine.

${ }^{21}$ AJ, 103-60, Dopis ambasadora Avakumovića od 25. aprila 1941 (bez delovodnog broja).

${ }^{22}$ O teritorijalnim ustupcima Kraljevine Rumunije 1940. godine više u: Giurescu Dinu, Romania in the Second World War:1939-1945 (New York: Columbia University Press, 2000).

${ }^{23}$ Istovremeno, jugoslovenska Vlada u emigraciji je pokušala da preko SSSR-a utiče na Rumuniju i Bugarsku da ne okupiraju delove Kraljevine. AJ, 103-60, Poverljivi telegram iz Jerusalima br. 99, 29. april 1941. 
SSSR-a evakuiše pisar Borivoje Simović, sin predsednika Vlade generala Dušana Simovića. Ambasador Avakumović je smatrao da je on neposredno ugrožen, iako se Rumunija nije vojno uključila u napad na Kraljevinu Jugoslaviju. ${ }^{24}$

$\mathrm{Na}$ tu ocenu ambasadora Avakumovića svakako je uticalo i pisanje rumunskih provladinih listova koji počinju da vode svojevrsnu kampanju, opravdavajući napad na Kraljevinu Jugoslaviju i pogrdno pišući o mladom kralju i njegovom „bekstvu“ iz zemlje sa Vladom. Takođe, otvaraju pitanja položaja Rumuna u istočnoj Srbiji, Banatu i Makedoniji (sic!). ${ }^{25}$ Isto tako, prenet je i govor poglavnika Pavelića i afirmativno je pisano o Nezavisnoj Državi Hrvatskoj (NDH). Iznose se tvrdnje da se Kraljevina Jugoslavija držala nelojalno prema Rumuniji. Kako bismo stekli detaljniji uvid u taj nedovoljno istražen arhivski materijal, ovde dajemo odabrane izvode iz pregleda štampe koji je priredila jugoslovenska Ambasada u Bukureštu. ${ }^{26}$

Rumunski listovi od 29. aprila donose vest da je u Temišvar stigla delegacija Rumuna iz istočne Srbije koja se uputila na sastanak sa generalom Antoneskuom i šefom nemačke vojne misije generalom Hanzenom. Oni su izjavili medijima da će tražiti pod nemačkim pokroviteljstvom ,prisajedinjenje Timočke Krajine Rumuniji, a što svi tamošnji Rumuni s nestrpljenjem očekuju“.

U pregledu rumunske štampe je stajalo: „List Kurentul u svom članku „Rumuni između Morave i Timoka i bogatstvo njihovog kraja“ ističe da su kako srpski naučnici kao na primer Cvijić, a zatim i srpske zvanične statistike bezobzirno smanjili broj Rumuna koji žive u Timočkoj Krajini, nastojeći da ovu prikažu kao mešovito naseljenu srpskim i, u manjoj meri, rumunskim elementom. Međutim, slučaj je bio potpuno protivan, jer se Rumuni u ovom kraju nalaze u kompaktnoj masi brojeći prema neutralnim istraživačima oko pola miliona duša, kao što potvrđuje i Italijan Atilio Tamaro. Ove srpske tendencije razumljive su kada se imaju u vidu neizmerna bogatstva ovih oblasti. Ovo naročito u rudama. U članku se zatim navodi opširno desetogodišnja proizvodnja bakra u Boru, pirita u Majdanpeku, lignita u Kostolcu i drugo i veli da bi prisajedinjenjem ove oblasti Rumuniji ne samo bila oslobođena porobljena braća već bi i Rumunija dobila ogromna bogatstva i prihode.

Akciunea objavljuje sličan napis veleći da dok bugarski naučnik Romanski govoreći o broju Rumuna u Timočkoj Krajini navodi brojno stanje u pojedinim naseljima kao na primer Slatini koja je potpuno rumunska, srpske statistike ovo isto mesto pominju kao naseljeno od 1.357 Srba i samo 50 Rumuna. Ovaj primer najbolje prikazuje režim pod kojim su živeli timočki Rumuni.

Akciunea u uvodnom članku „Timočki Rumuni“"veli da između Morave i Timoka živi oko pola miliona Rumuna, iako srpske zvanične statistike navode mnogo manji broj. Treba zahvaliti međutim nekim etnolozima, kao Bugarinu Romanskom, pa čak i Srbinu Tihomiru Đorđeviću, što su ovi falsifikati dema-

\footnotetext{
${ }^{24}$ AJ, 103-85, Izveštaj Avakumovića; AJ,103-85, Telegram pov. br. 75 iz Jerusalima, 24. april 1941.

${ }^{25} \mathrm{U}$ pitanju je ideja zastupljena u pojedinim krugovima Rumunije o tome da su svi potomci romanizovanog stanovništva do Grčke zapravo vezani za Rumuniju, poput Vlaha, Cincara itd.

${ }^{26}$ AJ, 103-60, Izveštaji o pisanju rumunskih medija 29. i 30. aprila 1941 (bez delovodnog broja).
} 
skirani. Tako na primer Romanski navodi u selu Krivelj 2.708 Rumuna, u srpskim statistikama od 1921. godine isto selo broji 2.572 Srbina a svega $14 \mathrm{Ru}-$ muna! Selo Tržani kod Požarevca predstavlja još teži primer bezobraznog falsifikovanja, jer dok Romanski ovde navodi samo nekoliko Bugara i 2.000 Rumuna $\mathrm{u}$ jugoslovenskim statistikama od 1921. godine ovde se nalazi 1.495 Srba $i$ samo 2 Rumuna!! List veli da danas posle raspada bivše Jugoslavije postoje na sreću mnogo ubedljivija sredstva da se dokaže pravo Rumunije na Timočki kraj.

Universul objavljuje članak ,Etničke granice na Balkanu“, iz pera g. Nikole Bacarije, koji veli da je teško povući besprekorne etničke granice bilo koje balkanske države, ali da svakako treba voditi računa da na Balkanu živi više stotina hiljada Aromuna i Rumuna, za koje danas treba naći specijalno rešenje situacije. Ovo rešenje pisac će predložiti u idućim brojevima lista“.

U izveštaju se navode još neki novinski izvodi, sa gotovo fantastičnim i sa današnjeg stanovišta potpuno neutemeljenim činjenicama. Tako list Kurentul objavljuje članak o potrebi stvaranja „nezavisne maćedonsko-albanske države“ na prostoru Albanije, Kosova i Metohije i Makedonije, u kojoj će učešće uzeti i „makedonski Rumuni“ i koja će se nalaziti pod protektoratom Italije. Drugi rumunski listovi pišu o tome da su Rumuni bili primorani da se bore u vojskama Kraljevine Grčke i Kraljevine Jugoslavije i da su to radili u skladu sa svojom „,kavaljerskom tradicijom“. ${ }^{27}$

U pregledu rumunske štampe od 30. aprila 1941. navodi se da ,rumunski listovi i nadalje nastavljaju bezobzirnu kampanju protiv Jugoslavije i Srba po pitanju rumunskih manjina u Timočkoj Krajini, koje su Srbi držali, vele listovi, u najtežem ropstvu. Činjenica da je u toku poslednjih dana u raznim listovima objavljeno nekoliko napisa doslovno i približno iste sadržine, najbolje pokazuje da se ova kampanja vodi po nalogu i uputstvima sa zvaničnog mesta i u cilju da bi se u rumunskom narodu stvorilo raspoloženje pogodno za zauzimanje neprijateljskog držanja Rumunije prema nama i okupiranja Timočke Krajine, a eventualno i Banata. Tako je danas u listovima Kurentul, Timpul i Akciunea objavljen isti napis doslovno jednake sadržine, a koji želi da dokaže da je Jugoslavija kroz 20 poslednjih godina zauzimala mučki neprijateljski stav prema Rumuniji, koju je prezirala. Dalje se veli da je još 1930. godine jedan rumunski publicista, dobar poznavalac Srba, upozorio rumunsku javnost da je Jugoslavija i pored saveza sa Rumunijom, (njen) najopasniji neprijatelj. Ovaj stav Jugoslavije lako je razumeti kad se uzme u obzir sistematsko stvaranje atmosfere putem štampe pa čak i putem školskih udžbenika...". ${ }^{2}$

I pored žestoke antijugoslovenske i antisrpske kampanje u pojedinim rumunskim medijima, iza koje su stajali Nemci, prema svedočenju ambasadora Avakumovića i sekretara Koste St. Pavlovića rumunski narod je ostao privržen tradicionalnom prijateljstvu sa Srbima. Najočiglednija manifestacija takvog stava bilo je ponašanje lokalnog stanovništva prema zarobljenim lađarima i vojnicima $\mathrm{i}$ oficirima za koje su nemačke snage formirale prolazne logore na

\footnotetext{
${ }^{27}$ AJ, 103-60, Izveštaji o pisanju rumunskih medija 29. aprila 1941 (bez delovodnog broja).

${ }^{28}$ AJ, 103-60, Poverljivi izveštaj iz Bukurešta br. 780, 30. april 1941.
} 
rumunskom tlu. Običan rumunski narod je doturao hranu i pored izričite nemačke naredbe da se to ne sme raditi. Zabeleženi su i fizički sukobi nemačkih vojnika s rumunskim vojnicima i oficirima zbog toga što su zarobljenim srpskim vojnicima kupovali i doturali hranu. Pomoć je dostavljala i jugoslovenska ambasada, a to su činili i istaknuti Rumuni i njihov Crveni krst. Ambasada je prilikom svog povlačenja organizovala da sav novac koji je imala na računu u lokalnoj valuti bude razdeljen zarobljenicima i povređenim pilotima. ${ }^{29}$

Posebno je ilustrativan bio slučaj poginulih pilota Jugoslovenskog kraljevskog vazduhoplovstva koji su u nekoliko incidenata od prvog dana rata stradali nad rumunskom teritorijom. Oni su sahranjivani najčešće uz vojne i civilne počasti i uz crkveni obred. Slikovit opis jedne od tih sahrana ostavio je Kosta St. Pavlović koji je zabeležio i nekoliko rečenica iz prigodnog govora lokalnog rumunskog sveštenika: „Zavetujem se predstavnicima Jugoslavije da ćemo moji seljaci i ja verno čuvati ostatke ovih divova koji su poginuli braneći Otadžbinu od neprijatelja čovečanstva Adolfa Hitlera“. Prilikom polaganja kovčega, četa vojnika je opalila počasni plotun u vazduh. ${ }^{30}$ Zbog odnosa prema preživelim pilotima, koji su nemački oficiri ocenili kao suviše blagonaklon i prijateljski, smenjen je komandant rumunskog konjičkog puka Kraljice Marije. ${ }^{31}$

Uprkos teškoćama, Ambasada je nastojala da nastavi rad i kontaktira rumunske zvaničnike. I posle 6. aprila održavaju se redovni diplomatski kontakti (ambasador Avakumović i diplomata Kosta Pavlović) sa najistaknutijim predstavnicima rumunskog Ministarstva inostranih poslova, Dvora i brojnim bivšim političarima koji su imali uticaja i na rumunskog kralja, poput bivših predsednika Vlade Julija Manijua i George Tatareskua, kao i bivšeg ministra inostranih dela Istrata Mičeskua. Uz to, nastavio se i vojnoobaveštajni rad vojnog izaslanika pukovnika Stropnika. ${ }^{32}$

Stalna saradnja je postojala i sa američkim poslanikom u Bukureštu Frenklinom Motom Gartnerom, koji se od samog početka postavio kao zaštitnik srpskih interesa, pa je bilo sasvim prirodno što je docnije, po prekidu jugoslovensko-rumunskih diplomatskih odnosa, poslanstvo Sjedinjenih Američkih Država (SAD) bilo određeno da se brine o zaštiti jugoslovenskih državljana u Rumuniji. ${ }^{33}$

Pokazalo se da je poslanstvo SAD u Rumuniji tu zaštitu veoma ažurno obavljalo. Prilikom evakuacije Ambasade Kraljevine Jugoslavije iz Bukurešta ono je i formalno preuzelo staranje o zaštiti interesa jugoslovenskih državljana u Rumuniji, kao i deo arhive iz jugoslovenskog diplomatskog predstavništva. Interesantan je podatak da je deo arhive Ambasade koji nije bio spaljen nego je ostavljen na čuvanje poslanstvu SAD već u julu 1941. evakuisan za Vašington i

\footnotetext{
${ }^{29}$ R. Radić, $n . d ., 303$.

${ }^{30}$ Isto.

${ }^{31}$ Vojni arhiv (VA), P-17, k. 8, f. 1, d. 7, Izjava vazduhoplovaca interniranih u Rumuniji data pukovniku Francetu Stropniku, 11; R. Radić, n. d., 264, 301; Miloš Žikić, n. d.

32 To se može zaključiti na osnovu Pavlovićevih dnevničkih zapisa, ali i kroz delimično sačuvanu arhivsku građu. AJ, 103-60.

${ }^{33}$ Prvu indiciju da poslanstvo SAD može da preuzme zaštitu jugoslovenskih interesa u Rumuniji nalazimo u depeši od 23. aprila 1941. AJ, 103-60, Šifrovani telegram Poslanstva u Moskvi br. 290, 23. april 1941.
} 
predat poslanstvu Kraljevine Jugoslavije u SAD. ${ }^{34}$ Američko poslanstvo je posredovalo kod rumunskih vlasti da bi se rešilo i pitanje evakuacije arhive, uz poštovanje diplomatskih normi predviđenih u takvim situacijama.

Ne bi bilo ispravno ako bismo rad Ambasade u danima nakon 6. aprila 1941. posmatrali kao normalan i uobičajen. Rumunija nije direktno uzela učešća u agresiji na Kraljevinu Jugoslaviju, ali je bila možda i najvažnija teritorija sa koje su nemačke snage izvršile napad. Postojanje više stotina hiljada nemačkih vojnika na teritoriji Kraljevine Rumunije diktiralo je i zvaničan stav prema jugoslovenskim državljanima koji su se zatekli na tlu Rumunije.

Ambasada u Rumuniji se po mnogo čemu razlikovala od većine drugih diplomatskih predstavništava Kraljevine Jugoslavije u zemljama članicama Trojnog pakta. Diplomate koje su do Aprilskog rata službovale u Italiji i višijevskoj Francuskoj imale su mogućnost da nesmetano odu u neutralnu zemlju po izboru. Većina ostalih nije bila te sreće. Diplomate iz okupiranog Pariza, Berlina, Praga, čak iz tek okupirane Atine bile su internirane na obali Bodenskog jezera i posle višenedeljnog čekanja i neizvesnosti nemačke vlasti su ih, uz obrazloženje da ne priznaju postojanje Kraljevine Jugoslavije, vratile specijalnim vozom za Beograd, gde su mnogi od njih uhapšeni, neki optuženi za špijunažu protiv Trećeg rajha i završili u istragama Gestapoa i po zatvorima i koncentracionim logorima. ${ }^{35}$

Diplomatskom osoblju iz Sofije i Budimpešte je dopušteno da odstupi ka Turskoj (27. aprila), poslanstvu u Višiju je obezbeđen put ka Portugaliji, diplomatskom predstavništvu iz Bratislave u SSSR, dok su samo tri predstavništva nastavila da rade u nekom periodu. Predstavništvo u Bukureštu je još nekoliko nedelja obavljalo svoju misiju. Nastavili su da rade poslanstvo u Vatikanu (mada je uskoro i odatle poslanik proteran u Portugaliju), kao i Generalni konzulat u Marseju, koji je izgubio konzularni status, ali je odlukom vlasti u Višiju nastavio rad. ${ }^{36}$

Prvi kontakt jugoslovenskih vlasti uspostavljen sa Ambasadom u Bukureštu nakon povlačenja kralja i Vlade iz Jugoslavije za koji imamo pismeni trag jeste telegram koji je preko Ankare (pretpostavljamo 21. aprila, jer dokument

\footnotetext{
${ }^{34}$ AJ, 103-60, Telegram poslanika Fotića pov. br. 385, 26. jul 1941.

${ }^{35}$ Problem proučavanja diplomatskih odnosa u ratnim sukobima predstavlja činjenica da je međunarodno kodifikovano običajno pravo koje tretira materiju uspostavljanja, kao i povlačenja priznanja i prekida diplomatskih odnosa dogovoreno među državama potpisnicama tek posle Drugog svetskog rata i to kroz Bečku konvenciju o diplomatskim odnosima (1961) i Bečku konvenciju o konzularnim odnosima (1963). Pre toga se primenjivala politika dobre prakse i uzajamnog poštovanja, a diplomate su (doduše nepisano) uživale imunitet na bilateralnom nivou i uz opšte uvažavanje njihovog statusa. Povrede tog statusa su bile izuzetno retke, gotovo na nivou incidenata, što su poštovale recimo sve strane u Velikom ratu. Treći rajh je pokazao znatno nepoštovanje dotadašnjih uzusa kada je ovako postupio sa jugoslovenskim diplomatama i konzularnim predstavnicima.

${ }^{36}$ Pitanje evakuacije jugoslovenskih diplomatskih predstavništava zaslužuje pažljiviju naučnu analizu. Podaci koji su ovde dati proistekli su iz detaljnog pregleda građe fondova Arhiva Jugoslavije u Beogradu, a pre svega fonda 103, Jugoslovenska vlada u emigraciji, ali i fonda Ministarstvo inostranih poslova Kraljevine Jugoslavije (334) kao i sačuvanih, mada znatno fragmentovanih arhivskih fondova pojedinih diplomatskih predstavništava Kraljevine Jugoslavije. Autor bliže istražuje taj kompleksan diplomatski i politički problem i namerava da u narednom periodu objavi uporednu analizu položaja našeg diplomatsko-konzularnog osoblja u pojedinim zemljama.
} 
nije signiran ni datiran) upućen Bukureštu. ${ }^{37} \mathrm{U}$ njemu se obaveštava ambasador Avakumović da je novo (privremeno) sedište državnih organa u Jerusalimu. Ta depeša, kao i većina depeša u narednim danima, ticala se eventualnog prekida diplomatskih odnosa zbog mogućeg priznanja NDH. ${ }^{38}$

Instrukcije koje je poslao ministar Ninčić bile su sasvim jasne: diplomatski odnosi se moraju nastaviti i pored teške situacije, osim u dva slučaja koji su predstavljali crvenu liniju: eventualna rumunska okupacija dela jugoslovenske teritorije ili priznanje NDH. One su u Bukurešt stigle 27. aprila, zajedno sa instrukcijom da se u tom slučaju diplomatsko osoblje evakuiše put Turske. Instrukcija je važila i za nastavnike i za činovnike rečne plovidbe. ${ }^{39} \mathrm{U}$ tom periodu je uništena kompletna politička arhiva Ambasade, kao i šifra i drugi poverljivi spisi. Nekoliko dana kasnije, 1. maja, stigla je instrukcija da se otpočne sa evakuacijom rezervnih oficira, intelektualaca i stručnjaka, poput mehaničara i $\mathrm{dr}^{40}$

I ambasador Avakumović traži poslednjeg dana aprila da se evakuiše deo personala iz Ambasade, nabrajajući trgovinskog predstavnika, nastavnike, većinu nižih diplomata i drugog osoblja. ${ }^{41}$ Cilj takve inicijative je da se spase bar deo ljudstva, u veoma teškim okolnostima, jer u tom trenutku potpuna evakuacija još nije bila izvesna. Interesantno je da ambasador pominje mogućnost da im Nemci ne dozvole da odu u neku treću zemlju, što se desilo u većini ostalih slučajeva. Dobio je dozvolu za takvu akciju od ministra Ninčića 4. maja.

Prema podacima Ambasade, početkom maja 1941. zateklo se na teritoriji Rumunije oko 200 članova Ambasade, njihovih porodica, nastavnika u srpskim školama i činovnika rečne plovidbe. ${ }^{42}$ Pored njih u Rumuniji se našlo oko 120 oficira i mornara brodova i šlepova koji su u trenutku napada rekvirirani i zadržani na rumunskoj strani Dunava. ${ }^{43}$

U uslovima izuzetno otežane komunikacije s Vladom koja se privremeno našla u Jerusalimu, za istoričare je interesantan još jedan podatak. U nekoliko depeša i pisama se pominje predstojeći napad na Sovjetski Savez nemačkih trupa stacioniranih na teritoriji Rumunije. ${ }^{44}$ Informiše se detaljno o brojnom

${ }^{37}$ Tog dana telegram iste sadržine upućen je u Atinu. AJ, 103-85, Šifrovani telegram od 20. aprila 1941.

${ }^{38}$ Postojao je i izvestan ,šum na vezama“ u takvim teškim okolnostima, o čemu svedoči telegram otpravljen 24. aprila iz Londona, u kome se obaveštava Bukurešt da ne mogu u potpunosti da dešifruju telegram otposlat iz Bukurešta za Vladu Kraljevine. AJ, 103-85, Telegram pov. br. 426, 24. april 1941.

39 Prema podacima Ambasade iz aprila 1941. godine, jugoslovenska kolonija u Bukureštu je brojala oko 3.000 ljudi, postojalo je još oko stotinu pripadnika rečne plovidbe i Dunavske komisije, kao i oko šezdeset srpskih učitelja u Banatu. AJ, 103-60, Nesignirani dokument od 25. aprila 1941 .

40 AJ, 103-35, Šifrovani telegram Momčila Ninčića Ankari, 1. maj 1941.

${ }^{41}$ AJ, 103-85, Šifrovani telegram iz Bukurešta, 30. april 1941. U njemu se, pored ostalog, obaveštava da je Rumunija zatvorila svoje diplomatsko predstavništvo u Beogradu.

42 Taj podatak nije u neskladu sa već ranije iznetim podacima.

${ }^{43}$ AJ, 103-85, Šifrovani telegram br. 706 iz Bukurešta, bez signiranog datuma.

${ }^{44}$ U pitanju je serija šifrovanih dopisa iz Ambasade u Bukureštu koji su bili upućeni diplomatskim predstavništvima Kraljevine Jugoslavije u Turskoj (Carigrad i Ankara) i u kojima se eksplicitno tražilo da se o tome obavesti jugoslovensko diplomatsko predstavništvo u Moskvi i poslanik Gavrilović, te da se o tome obaveste sovjetske vlasti. Prvi sačuvani telegram sa tom tematikom poslat je iz Buku- 
stanju nemačkih trupa, o njihovoj spremi i tehnici, kao i prostoru koji su u Rumuniji zaposele. Predviđa se i tačan datum kada bi napad mogao otpočeti i figurira 15. jun 1941, što je samo sedam dana pre datuma kada se taj napad zapravo i odigrao. ${ }^{45}$ Najdetaljnija od svih depeša sa tom tematikom bila je ona od 30 . aprila, koja je preko Ankare dostavljena Ninčiću u Jerusalimu. U opširnoj depeši koja je bila posvećena isključivo predstojećem napadu Nemačke i njenih saveznika na SSSR, na osnovu ,dobro obaveštenog izvora“46 taksativno se iznosi raspored nemačkih divizija i vazduhoplovnih snaga na teritoriji Rumunije. Izveštava se da su rumunske snage nedovoljno mobilisane i da je tim planom predviđeno da se one ne nađu u direktnoj akciji protiv SSSR-a, već kao posadne jedinice u Besarabiji. Posebno je zanimljivo to što su ti izvori predvideli i okviran (i pokazaće se prilično tačan) datum napada na SSSR.

I pored privremenog prekida diplomatskih odnosa sa SSSR-om u maju 1941. Vlada Kraljevine Jugoslavije je svakako tu informaciju prenela saveznicima, to jest Velikoj Britaniji. ${ }^{47} \mathrm{U}$ cilju bržeg slanja podataka, ostalo je zabeleženo da je Ambasada u Bukureštu te informacije i direktno dostavila Poslanstvu u Moskvi, kako bi što brže informisala vlasti SSSR-a. ${ }^{48}$ I narednih dana se upućuju telegrami iz Bukurešta, najčešće preko Turske, u kojima se izlažu dalji vojni podaci o predstojećem napadu na SSSR. Tako se informiše o izgradnji novih aerodroma, kao i o uspostavljanju saradnje rumunskog i nemačkog generalštaba oko izrade detaljnih planova napada na SSSR. Istovremeno se ukazuje i na to odakle stižu nemačke trupe u Rumuniju (prevashodno iz okupirane Francuske, ali i iz Nemačke). ${ }^{49}$

U prvim danima nakon Aprilskog rata Ambasada u Bukureštu, kao najbliža Jugoslaviji, šalje u Jerusalim podatke o posledicama bombardovanja Beograda i žrtvama, ali i privatne poruke drugih diplomatskih činovnika u Evropi za Beograd i teritoriju Srbije. Tako se 22. aprila preko Carigrada izveštava o svedočenju jednog državljanina SAD koji je 18. aprila 1941. došao u Rumuniju iz Beograda. Ambasada iz Bukurešta na osnovu njegovih utisaka sačinjava podroban izveštaj: „Užasi

rešta već 20. aprila 1941. i preko Ankare je 24. aprila prosleđen u Moskvu. U njemu se već iznose podaci o grupisanju nemačkih i rumunskih trupa u rumunskoj Moldaviji (23 divizije) i Dobrudži (4 divizije). U telegramu se prenose i informacije da nemački oficiri govore o predstojećem napadu na SSSR. AJ, 103-60, Strogo poverljivi šifrovani telegram br. 726, 20. april 1941.

${ }^{45}$ AJ, 103-60, Prenošenje podataka iz Bukurešta od 30. aprila 1941. u dopisu br. 683 iz Ankare od 2. maja 1941.

${ }^{46}$ Izvor tih informacija nije poznat, ali se navodi da ih je sakupio obaveštajni oficir i vojni izaslanik pukovnik France Stropnik. O obaveštajnim dužnostima jugoslovenskih vojnih izaslanika opširnije videti: Dalibor Denda, „Vojna obaveštajna služba u Kraljevini SHS/Jugoslaviji 19181941“, Vojnoistorijski glasnik, br. 2, (2010), 22-41. O Stropniku videti u: Aleksandar Životić, „Slovenci u vojnoj diplomatiji Kraljevine Jugoslavije“, Zgodovinski časopis, 73, 159, (2019), $138-156$.

${ }^{47}$ C̆ak i da to Ambasada Jugoslavije nije učinila, a nema nijednog valjanog razloga za takvu sumnju, ta informacija je svakako bila dostupna Velikoj Britaniji, jer su engleske vlasti pomno nadzirale sve komunikacije kako jugoslovenske vlade, tako i svih drugih vlada koje su se sklonile pod njenu zaštitu. Samim tim izvesno je da je o tome bila obaveštena i Moskva, odnosno sam Staljin.

${ }^{48}$ AJ, 103-60, Informacija Ambasade u Turskoj pov. br. 605, 6. maj 1941.

${ }^{49}$ AJ, 103-60, Telegram iz Ankare pov. br. 695, 6. maj 1941. 
bombardovanja prevazilaze one u Varšavi. Još ima leševa na ulicama. Pune bolnice za koje se Nemci ne staraju. Sve radnje opustošene i Nemci kamionima nose pljačkane stvari. Zaostali naši ljudi drže se hrabro i solidarno. Sva tri mosta kod Beograda su porušena. Naši uništili vojnu flotilu (rečnu - prim. R. M.). Železnička pruga Beograd-Skoplje potpuno razorena“. ${ }^{50}$ Prvog dana maja Ambasada u Bukureštu javlja o prvim zločinima ustaša nad Srbima na prostoru Hrvatske. I tu se navodi da su „Srbi u prečanskim krajevima izloženi gonjenju ustaša“ 51

Deset dana nakon instrukcije ministra Ninčića, 6. maja 1941, Rumunija je priznala NDH, čime su se stekli uslovi za prekid diplomatskih odnosa. ${ }^{52} \mathrm{Na}-$ rednog dana pripremljeno je pismo adresovano na generala Antoneskua, koje je potpisao ambasador Avakumović. U njemu se navodi da je nakon priznanja NDH od strane rumunske Vlade, kao i zbog toga što je rumunska teritorija korišćena u napadu na Kraljevinu Jugoslaviju aprila 1941. godine, nemoguće nastaviti diplomatske odnose dve zemlje, te se oni stoga prekidaju. ${ }^{53}$ General Antonesku se $u$ tom trenutku nije nalazio u Bukureštu pa nije mogao da primi $u$ audijenciju ambasadora Avakumovića, koji je hteo da mu lično uruči pismo. Posle više intervencija iz jugoslovenske Ambasade, zakazan je sastanak s pomoćnikom ministra inostranih poslova Krecijanuom u večernjim satima 9. maja.

Ostao nam je dostupan detaljan izveštaj koji je ambasador ostavio nakon tog sastanka. ${ }^{54} \mathrm{U}$ razgovoru je podvukao da priznanje NDH predstavlja neprijateljski akt prema Jugoslaviji pa je stoga Kraljevska jugoslovenska vlada primorana da prekine diplomatske odnose sa Kraljevinom Rumunijom. Ambasador je naglasio i da su nemački avioni koji su u Aprilskom ratu napali Beograd poleteli iz Rumunije, kao i da su neprijateljske trupe prešle na jugoslovensku teritoriju i sa rumunske teritorije. Rumunski sagovornik Krecijanu je istakao da žali što je do toga došlo, ali da za to nisu krivi Rumuni, već „fatalni tok događaja izazvan od strane Nemačke“. Potom je dodao: „Šta ćete? Osećaj naroda i tradicije naših odnosa su jači od politike koju Vlada sada mora da vodi““.55 To je svakako odstupalo od očekivanih izjava saveznika Trećeg rajha. Avakumović je tom prilikom zahvalio na stavu širokih rumunskih krugova, rumunskog Crvenog krsta i rumunskih seljaka prema jugoslovenskim zarobljenicima. Tražio je da se dozvoli izlazak u treću zemlju kako diplomatskog i konzularnog osoblja, tako i učitelja i posluge (kao takav izveden je iz Rumunije jedan jugoslovenski oficir koji je prethodno neprimećen izbegao u Rumuniju). Nakon što je to odobreno, molba je proširena kako bi se olakšalo jugoslovenskim državljanima koji beže od mađarskog terora u Rumuniju da preko Konstance odu u Tursku. To je bilo jedino pitanje za koje na ovom sastanku nije ponuđeno rešenje.

\footnotetext{
${ }^{50}$ AJ, 103-60, Šifrovani telegram iz Carigrada, 22. april 1941.

${ }^{51}$ AJ, 103-60, Šifrovani telegram iz Ankare.

${ }^{52}$ Rumunska vlada je u noći 6/7. maja 1941. objavila tekst razmene telegrama Pavelić-Antonesku kojim Rumunija priznaje Nezavisnu Državu Hrvatsku.

${ }^{53}$ Postojalo je nekoliko nacrta tog pisma, različitih po oštrini, ali veoma sličnih po formi. Više o tome: R. Radić, $n$. d., 265-267.

${ }^{54}$ AJ, 103-60, Izveštaj ambasadora Avakumovića iz Tel Aviva, 29. maj 1941.

${ }^{55}$ Isto.
} 
Posle tri dana u Bukurešt se vratio general Antonesku koji je odmah primio odlazećeg ambasadora Avakumovića. Razgovor je, prema jedinom dostupnom izvoru, bio iskren i veoma otvoren. ${ }^{56}$ General Antonesku je podsetio ambasadora da ga je odmah nakon puča upozorio na napad na Kraljevinu Jugoslaviju i podvukao da je za interes Rumunije bilo važno očuvanje Jugoslavije. Istakao je i da je situacija u tom trenutku takva da Jugoslavija više ne postoji, Rumunija je izgubila deo svojih teritorija, a Bugarska i Mađarska su proširene i ojačane i obe su zauzele delove teritorija Kraljevine Jugoslavije, ali i Kraljevine Rumunije. On je ukazao na vojnu superiornost Nemačke, posebno u kopnenim snagama, i izneo predviđanje da će Nemačka pobediti, ali je na Avakumovićevo iznenađenje ostavio i mogućnost nemačkog poraza u ratu, ako bi se intenzivno bombardovali nemački gradovi, što bi moglo da dovede do zamora nemačkog stanovništva i gubitka volje za daljim ratovanjem. Ponovio je garancije za dozvolu da se jugoslovenske diplomate povuku u Tursku, dodajući da će uzeti pod svoju zaštitu porodice jugoslovenskih činovnika u Bukureštu. Složio se da činovnik ambasade Novak Popović bude pridodat Američkom poslanstvu u Bukureštu, kako bi ostao da čuva zgradu Ambasade Kraljevine Jugoslavije u Bukureštu. ,Vama su bar poznati osećaji rumunskog naroda za Srbe“, podvukao je na samom kraju razgovora general Antonesku. ${ }^{57}$

Interesantan je izveštaj o oproštajnoj poseti ambasadora Avakumovića rumunskom kralju Mihailu (Mihaju). Iako nije bilo u skladu sa diplomatskim običajima da kralj prima odlazećeg ambasadora prilikom prekida odnosa, nekoliko sati pred evakuaciju jugoslovenskog diplomatskog osoblja stigao je poziv za audijenciju ambasadora Avakumovića kod kralja. Tom prilikom kralj je izrazio nezadovoljstvo prekidom odnosa izazvanim nemačkim prisustvom u Rumuniji. Istakao je da je ,sve ovo što se dešava između Jugoslavije i Rumunije velika tragedija i da za to ne treba kriviti rumunski narod“. ${ }^{8}$ Prilikom tog oproštajnog susreta rumunski kralj je uputio pozdrave svom rođaku (bratu od tetke), jugoslovenskom kralju Petru II Karađorđeviću.

Diplomatski personal se u velikoj većini povukao u Tursku. Izuzetak je bio činovnik Novak Popović, koji je ostavljen da čuva zgradu i kao takav je uvršten u diplomatsku listu poslanstva SAD. ${ }^{59}$ On je preuzeo čuvanje interesa Jugoslavije u Rumuniji. Jedini koji je odbio da se evakuiše bio je ekonomski savetnik ambasade Dragutin Kulmer. On se izgovorio zdravstvenim stanjem, a za taj čin je dobio posebnu saglasnost, doduše post festum (31. maja) kada mu je ministar Ninčić odobrio da ostane u Rumuniji. ${ }^{60}$ To je opravdano ,hrvatskim razlozima“ 61

\footnotetext{
${ }^{56}$ Isto.

${ }^{57}$ Isto.

${ }^{58}$ Isto.

${ }^{59}$ O Popovićevoj daljoj sudbini, obaveštajnom radu za Vladu u emigraciji preko majora Vladimira Perića u Carigradu, hapšenju koje je izvršio Gestapo i boravku u logoru Dahau, više u: K. St. Pavlović, Onakvi kakve sam ih znao, 191-196.

${ }^{60}$ AJ, 103-65, Dopis Poslanstvu u Ankari pov. br. 687, 5. jun 1941.

${ }^{61}$ AJ, 103-65, Molba Dragutina Kulmera od 11. maja 1941; Isto, Depeša iz Jerusalima br. 681, 5. jun 1941; K. St. Pavlović, Ratni dnevnik 1941-1945, 98.
} 
Osim diplomatskog i konzularnog osoblja, dozvoljena je evakuacija nastavnika srpskih škola, koji su do 14. maja morali sami da dođu do Bukurešta. Sa njima se povukao i agent rečne plovidbe iz Temišvara, jer ostali nisu uspeli da dođu do Bukurešta. Deo posade sa brodova se odvojeno povukao u Odesu.

Evakuacija je izvršena odmah iza ponoći 15. maja 1941, specijalnom železničkom kompozicijom koju je obezbedila rumunska Vlada, u pravcu Konstance. Posle dana provedenog u gradu, rumunskim brodom „Kralj Karol“ otisnuli su se put Carigrada. Poslednji pogled na teritoriju Rumunije koju su napuštali bio je pogled na svetionik ispred luke, koji je obezbeđivao nemački vojnik u punoj opremi, kao i na protivvazdušne baterije nemačke vojske, kako beleži Kosta Pavlović. ${ }^{62}$

Kako saznajemo iz izveštaja Generalnog konzulata Kraljevine Jugoslavije u Carigradu, u taj grad je stigao transport sa 100 lica iz Bukurešta među kojima su se nalazili kako diplomatsko osoblje i njihove porodice, tako i drugi državljani (nastavnici i ostali) koji su organizovano izvedeni iz Rumunije. Oni su uz podršku Velike Britanije bili evakuisani za Jerusalim i Kairo. ${ }^{63}$

$\mathrm{Za}$ istraživače je zanimljiv i podatak da je Kraljevina Rumunija želela da izbegne javno objavljivanje informacije o prekidu diplomatskih odnosa $\mathrm{s}$ Kraljevinom Jugoslavijom. Iako je nota kojom su prekinuti diplomatski odnosi upućena 7. maja, a Ambasada se evakuisala 14. maja 1941, ta informacija nije bila publikovana. Možemo da pretpostavimo da rumunskoj strani taj prekid u najmanju ruku nije bio prijatan i svakako je bio u suprotnosti sa 100 -godišnjim diplomatskim odnosima dve susedne države. ${ }^{64}$

\section{Zaključak}

U istoriji nije nepoznato da se prijateljski narodi i zemlje nađu u ratnim sukobima na različitim stranama. Posmatrajući odnose Kraljevine Jugoslavije i Kraljevine Rumunije može se zaključiti da osim dinastičkih, političkih i ekonomskih veza, postoji i uzajamno prijateljstvo dva većinska naroda.

Postupak rumunske Vlade nakon napada Nemačke i Italije sa saveznicima na Kraljevinu Jugoslaviju razlikovao se od postupaka svih ostalih zemalja potpisnica Trojnog pakta. General Antonesku nije poslao vojne jedinice preko granične crte ni tokom Aprilskog rata, ni nakon sloma jugoslovenske vojske. Kako navodi diplomata Kosta St. Pavlović, Antonesku nije hteo da okupira ni Banat kada su se jugoslovenske trupe bez borbe povukle iz njega, a i kada je reč o priznavanju NDH, pokušao je da dobije na vremenu, tako da je Rumunija poslednja među svim državama potpisnicama Trojnog pakta priznala NDH. Pavlović u svojim sećanjima, kasnije pretočenim u više dela, ocenjuje da je Antonesku tako postupio zbog toga što je znao da to rumunski narod ne odobra-

\footnotetext{
${ }^{62}$ K. St. Pavlović, Ratni dnevnik 1941-1945, 15.

${ }^{63}$ AJ, 103-35, Ninčićev šifrovani telegram od 18. maja 1941.

${ }^{64}$ Upravo aprila 1941. bilo je predviđeno obeležavanje jednog veka od uspostavljanja diplomatskih odnosa.
} 
va, kao i da to može naneti nepopravljivu štetu odnosima dva naroda nakon rata. Za razliku od većine saveznika Trećeg rajha, Rumunija je omogućila nesmetanu evakuaciju jugoslovenskih diplomata i državljana, a izjave rumunskih zvaničnika, pa i samog rumunskog kralja ozbiljno su odstupale od retorike koja je dolazila iz Berlina i koja se svakako očekivala od nemačkih saveznika. Te izjave su išle dotle da su predviđale nastavak prijateljskih odnosa nakon rata, za koji sam Antonesku nije isključivao mogućnost da ga Nemačka i izgubi.

Nastavak rada ambasade Kraljevine Jugoslavije u Bukureštu više od četrdeset dana od početka Aprilskog rata pomogao je kraljevskoj Vladi koja se našla u izbeglištvu na Bliskom istoku da dobije prva pouzdana saznanja i iscrpne izveštaje o dešavanjima u zemlji, ratnim razaranjima u Srbiji i počecima progona srpskog življa u tek uspostavljenoj Nezavisnoj Državi Hrvatskoj.

\section{REFERENCE}

- Delent, Dennis. Hitler's Forgotten Ally: Ion Antonescu and His Regime, Romania, 1940-1944. London: Palgrave Macmillan, 2006.

https://doi.org/10.1057/9780230502093

- Denda, Dalibor. „Vojna obaveštajna služba u Kraljevini SHS/Jugoslaviji 1918-1941“. Vojnoistorijski glasnik, br. 2, (2010), 22-41.

- Đuričić, Mladen St. Istorija jugoslovenskog rečnog brodarstva do 1926. godine. Beograd: Zavod za izdavanje udžbenika, 1965.

- Giurescu, Dinu. Romania in the Second World War:1939-1945. New York: Columbia University Press, 2000.

- Gulić, Milan. Kraljevina Jugoslavija i Dunav. Beograd: Institut za savremenu istoriju, 2014.

- Čolović, Danica-Kaća, Srđan Čolović. Marija Karađorđević, Kraljica-Majka. Beograd: Arhiv Srbije, 2001.

- Marinković, Aleksandar. Ženidba kralja Aleksandra. Beograd: Vajat, 2004.

- Mićić, Srđan. Od birokratije do diplomatije - istorija jugoslovenske diplomatske službe 1918-1939. Beograd: Institut za noviju istoriju Srbije, 2018.

- Mitrović, Andrej. Razgraničenje Jugoslavije sa Mađarskom i Rumunijom. Novi Sad: Prometej, 2019.

- Pavlović, Kosta St. Ratni dnevnik 1941-1945. Beograd: Otkrovenje/Službeni glasnik, 2011.

- Pavlović, Kosta St. Onakvi kakve sam ih znao. Beograd: Otkrovenje, 2004.

- Pečikan, Ovidiju. Istorija Rumuna. Beograd: Klio, 2015.

- Radić, Radmila. „Sećanje Koste St. Pavlovića“. Tokovi istorije, br. 1-2, (2009), 249-304.

- Stanković, Đorđe. Nikola Pašić, saveznici i stvaranje Jugoslavije. Beograd: Nolit, 1984.

- Stojadinović, Milan. Ni rat ni pakt: Jugoslavija između dva rata. Rijeka: Otokar Keršovani, 1970. 
- Terzić, Velimir. Slom Kraljevine Jugoslavije 1941. Uzroci i posledice poraza, knjiga 2. Ljubljana-Beograd-Titograd: Narodna knjiga-Partizanska knjigaPobjeda, 1984.

- Žikić, Miloš. Na sporednom frontu - Aprilski rat i jugoslovensko-rumunski odnosi, zbornik radova sa bilateralnog skupa Instituta za savremenu istoriju i Univerziteta u Klužu, Kluž: Univerzitet u Klužu, 2019. (u štampi).

- Životić, Aleksandar. „Slovenci u vojnoj diplomatiji Kraljevine Jugoslavije“. Zgodovinski časopis, 73, 159, (2019), 138-156.

RATOMIR MILIKIĆ, PhD, Senior Research Associate Institute for Contemporary History

Belgrade, Republic of Serbia

rasamilikic@gmail.com

\section{WITHDRAWAL OF YUGOSLAV DIPLOMATIC PERSONNEL FROM THE KINGDOM OF ROMANIA IN 1941}

The author endeavors to recreate the withdrawal of Yugoslav diplomats from the mission to the Kingdom of Romania, which differed from the diplomatic offices in other states that had turned hostile overnight. Most of the diplomatic/consular staff and other citizens who found themselves caught in Romania, retreated toward either Turkey or Odessa. Those who reached Istanbul placed themselves at the service of the Yugoslav Government-In-Exile. It was not before May 14, 1941, more than a month after the invasion of Yugoslavia, that the Kingdom of Romania denied hospitality to the Yugoslav diplomatic/consular personnel. Moreover, it did not send them to Germany to join the large group of less fortunate diplomats destined for years under occupation or in concentration camps, but to neutral states instead. The paper relies on the archives of the Yugoslav Government-In-Exile, as well as the diaries of Kosta St. Pavlović, who served as a diplomat in Bucharest when the war broke out.

KEYWORDS: Kingdom of Yugoslavia, Kingdom of Romania, Diplomacy, World War II, Withdrawal of Diplomatic Personnel, Severance of Bilateral Ties 